\title{
A Rolling Horizon Based Algorithm for Solving Integrated Airline Schedule Recovery Problem
}

\author{
Dong Zhang and Henry Y. K. Lau \\ The University of Hong Kong, Hong Kong \\ Email: zd.pony@gmail.com, hyklau@hku.hk
}

\begin{abstract}
Airline disruption incurred huge cost for airlines and serious inconvenience for travelers. In this paper, we study the integrated airline schedule recovery problem, which considers flight recovery, aircraft recovery and crew recovery simultaneously. First we built an integer programming model which is based on traditional set partitioning model but including flight copy decision variables. Then a rolling horizon based algorithm is proposed to efficiently solve the model. Our algorithm decomposes the whole problem into smaller sub-problems by restricting swapping opportunities within each rolling period. All the flights are considered in each sub-problem to circumvent 'myopic' of traditional rolling horizon algorithm. Experimental results show that our method can provide competitive recovery solution in both solution quality and computation time.
\end{abstract}

Index Terms - airline recovery, flight recovery, crew recovery, rolling horizon

\section{INTRODUCTION}

Airline scheduling has far been the primary focus both in academic research and industrial application because it is essential for profit, service level, competitiveness of airline in the competing market. On-time performance of airlines schedule is key factor in maintaining satisfaction of current customers and attracting new ones. However, airline planned schedules are often subjected to numerous sources of irregularity such as adverse weather, air traffic congestion, aircraft mechanical problems, crew member's absence, propagated delay from upstream, longer passenger embarking and disembarking time and so on[1]. Delay and cancellation of flights are commonplace every day. Most disruptions in airline are attributed to two main causes[2]: (1) Airline resource shortages; (2) Airport and airspace capacity shortage.

Huge loss caused by airline disruption attracted researchers from industries and academy to study airline schedule recovery problem which aims to re-allocate and re-schedule resources to minimize total delay and other objectives. In this research, an integrated recovery model simultaneously considering flight, aircraft and crew recovery is proposed. Airport landing capacity, departing capacity and gate availability are explicitly incorporated 2013 when making recovery decision, which can facilitate airline efficiently allocating scarce airport resource to flights. A rolling-horizon based algorithm is proposed to solve this integrated model efficiently.

The following part is organized as follows: Section 2 is the background of airline recovery problem. Section 3 is mathematical model. Section 4 illustrates a rolling-horizon based algorithm to solve integer programming model proposed in section 3. Section 5 is experimental results. Section 6 is conclusion of this paper.

\section{BACKGROUND}

Once disruption occurred, Airline Operations Control Center (AOCC) is responsible for centrally controlling airline operations of resources which include aircrafts, crews and passengers. Operation controllers face a myriad of options to deal with various disruptions, including holding delayed flight legs until resources are ready to be operated; cancelling flight legs; swapping resources (aircraft, crew and passenger) between two flights; postponing the departure times of flight legs departing a hub airport to prevent connecting passenger missing their connections, etc. Objectives of recovery scheme are to decrease airline operating cost, flight delay and cancellation cost while increase passenger's satisfaction. Because of dynamic characteristic of airline operational control, real-time information about each airline resource is necessary when making recovery decision.

Whole airline recovery problem is extremely complex since combinatorial nature leads to huge number of possible solutions. In current practice, airline schedule recovery is performed in a sequential manner. The first step is to recover aircraft and make decision of flight leg cancellation, delays and aircraft rerouting. The second step is to determine crew recovery plans, recovering uncovered flight legs by reassigning current crews or utilizing reserve/standby crews. The third step is to develop passenger re-accommodation plans for disrupted passengers.

A large amount of literature can be found related to airline recovery problem for specific stage. For aircraft recovery problem we refer to Teodorovic and Guberinic [3], Teodorovic and Stojkovic [4], Teodorovic and stojkovic [5], Jarrah [6], Cao and Kanafani [7], [8], Yan and Yang [9], Yan and Tu [10], Yan and Lin [11], Thengval [12], Bard, Yu and Arguello [13], Eggenberg [14], Rosenberger [15], Clarke [16] and Arguello [17] and 
for crew recovery problem we refer to Wei [18], Stojkovic [19], Abdelghany [20], Lettovsky [21], Nissen [22].

Although the sequential method is quite efficient, the disadvantage is obvious. Since solution space is significantly limited by solution obtained in the previous step, solution quality might be not good and in some situations it is even hard to find a feasible one. In practice, communication and iteration between different steps is necessary to find a feasible solution but quick response and solution quality is not guaranteed. Recently, researchers begin to study integrated airline recovery problem which considers all the resources recovery simultaneously. To our knowledge, only Lettovsky [23], Petersen [24], Eggenberg [25], Abdelghany [26] pioneered research in integrated airline recovery and there is still much room left for further research both in models and solution methodologies. In this study, we will propose a different model and solution algorithm to solve integrated airline recovery problem.

\section{MODEL}

Notations used in the model are defined as following:

$\mathrm{F}$ : set of all flights which is indexed by $\mathrm{f}$

$\mathrm{FC}_{\mathrm{f}}$ : set of all flight copies of $\mathrm{f}$, which is indexed by fc

$\mathrm{K}$ : set of all resource types, which is indexed by $\mathrm{k}$

$\mathrm{R}_{\mathrm{k}}$ : set of all resources belonged to resource type $\mathrm{k}$, which is indexed by $r_{k}$

$\mathrm{R}$ : set of all airline resources which is indexed by $r$

$\mathrm{P}_{\mathrm{r}}$ : set of candidate routes of resource $r$, which is indexed by $p$

$\mathrm{C}_{\mathrm{p}}$ : set of all flight connections contained in path pwhich is indexed by c. For example, a path p contains four flights $\left(f_{1}, f_{2}, f_{3}, f_{4}\right)$, there are three flights connections within this path $\left(f_{1}, f_{2}\right),\left(f_{2}, f_{3}\right)$ and $\left(f_{3}, f_{4}\right)$

$\left[\mathrm{T}_{\mathrm{s}}, \mathrm{T}_{\mathrm{e}}\right]$ : recovery time window, $\mathrm{T}_{\mathrm{s}}$ is the start time of disruption, $\mathrm{T}_{\mathrm{e}}$ is the end time of recovery

$\operatorname{dep}_{\mathrm{fc}}$ : scheduled depart time of flight copy fc

$\operatorname{arr}_{\mathrm{fc}}$ : scheduled arrival time of flight copy fc

$\tau_{\mathrm{p}}$ : cost of route $\mathrm{p}$

$\sigma_{\mathrm{f}}$ : cancel cost of flight $\mathrm{f}$

$\mathrm{d}_{\mathrm{fc}}$ : delay cost of flight copy fc

$\alpha_{\mathrm{f}}^{\mathrm{p}}=1$ indicates flight $\mathrm{f}$ is contained in the route $\mathrm{p}, 0$ otherwise

Conn $_{\mathrm{r}}$ : minimum resource connection time

UA : set of available airport arrival slots, which is indexed by ua

UD: set of available airport departure slots, which is indexed by ud

UG: set of available airport gates, which is indexed by ug

$\mathrm{FC}_{\mathrm{ua}}$ : set of flight copies using arrival slot ua

$\mathrm{FC}_{\mathrm{ud}}$ : set of flight copies using departure slot ud

$\mathrm{FC}_{\mathrm{ug}}$ : set of flight copies using gate ug

$\mathrm{Cap}_{\mathrm{ua}}$ : capacity of arrival slot ua

Cap $_{u d}$ : capacity of departure slot ug

Cap $_{\text {ug }}$ : capacity of gate

Decision variables:

$\mathrm{X}_{\mathrm{p}}=1$ indicates resource routep is chosen, 0 otherwise;
$\mathrm{Z}_{\mathrm{f}}=1$ indicates flight $\mathrm{f}$ is chosen, 0 otherwise;

$\mathrm{Y}_{\mathrm{fc}}=1$ indicates flight copy $\mathrm{fc}$ is chosen, 0 otherwise;

The integrated airline recovery problem (IARP) can be formulated as:

$\min \sum_{p \in P} \tau_{p} X_{p}+\sum_{f \in F} \sum_{f c \in F C_{f}} d_{f c} Y_{f c}+\sum_{f \in F} \sigma_{f} Z_{f}(3.1)$ subject to:

$$
\begin{gathered}
\sum_{k \in K} \sum_{r_{k} \in R_{k}} \alpha_{f}^{p} X_{p}+Z_{f}=1 \forall f \in F \text { and } \forall k \in K \\
\sum_{f \in F} \sum_{f c \in F C_{f}} Y_{f c}+Z_{f}=1 \forall f \in F \\
\sum_{f_{s}^{\prime} \in F C_{f_{s}}} \operatorname{arr}_{f_{s}^{\prime}} Y_{f_{s}^{\prime}}+\operatorname{Conn}_{r} \leq \sum_{f_{t}^{\prime} \in F C_{f_{t}}} \operatorname{arr}_{f_{t}^{\prime}} Y_{f_{t}^{\prime}}+ \\
\mathrm{M}\left(1-X_{p}\right) \forall\left(f_{s}, f_{t}\right) \in C_{p}, p \in P_{r}, r \in R \\
\sum_{p \in P_{r}} X_{p} \leq 1 \forall r \in R \\
\sum_{f c \in F C_{u a}} Y_{f c} \leq \operatorname{Cap}_{u a} \forall u a \in U A \\
\sum_{f c \in F C_{u d}} Y_{f c} \leq \operatorname{Cap}_{u d} \forall u d \in U D \\
\sum_{f c \in F C_{u g}} Y_{f c} \leq \operatorname{Cap}_{u g} \forall u g \in U G
\end{gathered}
$$

Objective function (3.1) contains three parts which are operating cost of resource path, delay cost of flights and cancellation cost of flights; Constraints (3.2) is flight coverage constraint which forces for each resource type, every flight is either covered by one resource route belonged to this resource type or cancelled. Constraint (3.3) states that at most one flight copy of each flight can be chosen; Constraint (3.4) states connection feasibility, $\mathrm{M}$ is a very large positive number. If one path is chosen, then for each connection contained by this path, summation of arrival time of proceeding flight and minimum resource connection time must be smaller than departure time of succeeding flight; Constraint (3.5) states that each resource can be assigned to at most one resource path; Constraints (3.6-3.8) state airport capacity constraints, constraint (3.6) restricts number of selected flight copies using particular arrival slot is smaller than corresponding arrival slot capacity, constraint (3.7) restricts number of selected flight copies using particular departure slot is smaller than corresponding departure slot capacity, constraint (3.8) restricts number of selected flight copies using particular gate is smaller than corresponding gate capacity.

Major difference of our model with traditional set partition model for airline scheduling and recovery problem is that flight delay is not fixed when constructing new route, however, delay is also built as decision variable in the model. Advantage of this setting is that number of possible resource routes decreases exponentially since all the delay copies for particular flight are regarded as homogeneous when constructing routes. In addition, consistency of flight delay among different resource network is naturally represented by flight delay decision variable. Network flow connection constraints can be easily constructed similar to traditional network flow. In our model, constraint (3.4) is to force flights connection feasibility within each route and constraint (3.3) is to constraint that only once delay value can be selected for each flight.

It is necessary to note that since flight delay is unknown when constructing resource route, resource specific constraints related to daily duty/week/month duty time can't be exactly evaluated in the construction phase. To deal with this shortage, a dummy return flight is added in 
the end of each resource route. The departure time and arrival time of dummy return flight is identical and is set as latest duty end time of resource route belonged to. Connection time between normal flight and dummy return flight is zero. By restricting flights connection feasibility within each route, specific duty time constraint of each resource can be considered.

\section{ROLling HORIZON BASED ALGORITHM}

One possible way to solve previous model is to list all possible resources routes and then directly solve integer programming model. Since combinatorial nature, number of possible resources routes is huge, for a small scale airline schedule, there might be 10,000 possible paths and for a major hub-and-spoke airline, the number may even be larger than a hundred million. To make solution tractable, two traditional methods are:

1) Delayed column generation, in such approach only a subset of resource routes are generated as master problem, then sub-problem is solved to iteratively generate new routes based on dual information of master problem. Sub-problem is usually formulated as resources constrained shortest path problem, dynamic programming, constraint programming or integer programming can be used to solve shortest path problem. We refer Barnhart[27] about detailed information of Column Generation.

2) Decreasing solution space by limiting resources included in recovery phase. This method only selects directly affected resources and several unaffected resources capable of providing swapping opportunities. We refer to Rosenberger[15] about implement of this method.

Convergence speed of the first method is relatively slow which makes is inappropriate for airline recovery problem. For airline operation control center coordinator, short response is more important than global optimal solution. In some situations, even partial solution is better than no solution. The second method can provide a recovery solution within short time although this solution is not global optimal. The most difficult thing is to devise efficient solution space decreasing scheme.

\section{A. Rolling Horizon Based Algorithm}

Before introducing detailed procedures of this algorithm, several sets and parameters are defined previously:

Candidate Flight Set (CFS): set of all candidate flights within recovery time window

Candidate Route Set (SPS): set of routes generated in each rolling period

Cancelled Route Set (CPS): set of cancelled partial routes in previous rolling period

Rolling Period Length (RPL): duration of each rolling period

The detailed procedures of algorithm are as following:

1) Add all the flights with departure time among recovery period into Candidate Flight Set;
Initialize Candidate Route Set and Cancelled Route Set to be empty; preset length of rolling period; set original resources routes as current solution;

2) Divide whole recovery period into several rolling periods and set first period as current period;

3) Generating candidate routes based on current solution and Cancelled Route Set. Generated candidate routes are put into Candidate Route Set. Details about routing generating are illustrated in next section;

4) Check feasibility of routes in Candidate Route Set. Routes violating resource specific constraints are eliminated from Candidate Route Set;

5) Evaluate cost for routes in Candidate Route Set. As discuss previously, route cost consists two parts which are swapping cost and deadhead cost;

6) Solve the IARP based on Candidate Route Set and find optimal combination of resources route and exact delay value for each flight;

7) Update current solution and flight delay according to optimal solution, add partial routes cancelled in current rolling period into Cancelled Route Set; The reason why we use cancelled partial route rather than cancelled flights is that nature of our algorithm causes cancellation happened as unit of partial route rather single flight. Once a flight is cancelled, partial route this flight belonged to must also be cancelled. Advantage of considering cancelled partial route as a unit is that all the flights in cancelled route can be pulled back from cancellation by one swap operation with another partial route in the following period given new found partial route has less cancellation cost.

8) If current period is already last rolling period or no flight in the following rolling periods is delayed anymore, end algorithm; otherwise go to step (2);

\section{EXPERIMENTAL RESULTS}

Our testing data is from a hub-and-spoke regional airline in the US with 351 daily flights, 70 aircrafts belonging to fleet type and 134 crews. Since there is only one fleet type, we assume crew can operate all the aircrafts. Whole airline network contains two hub stations which are DFW and ORD. We found our results using a 3.4G Intel Core i7-3770 CPU, Ilog Cplex and Java Programming. Several disruption scenarios are simulated to test performance of our algorithm. All these disruption scenarios are categorized into two types: Ground Delay Program and Temporary Airport closure. Table I and Table II describe detailed information of each disruption scenario.

Solution of "push back" strategy is used to compare with solution rolling horizon based algorithm. "Push back" strategy only considers one recovery option which is delaying flight until all the resources are ready to depart. In the following text, "PB" is short for push back strategy 
and "RHAR" is short for rolling horizon based airline recovery algorithm.

Overall performance of our algorithm on all six events in scenario 1 in illustrated in table III. Results reveal that our rolling horizon based algorithm can solve all 9 different disruption scenarios efficiently. For small scale disruption events, solution can be given within seconds and for large scale disruption solution can also be given within 2 minutes. No flight is cancelled among all 9 events. In two events, crews are deadheaded since significant delay is saved by swapping. We can also found that run time is related to number of flights impacted and total delay in original schedule. In the most series event gdp_9, 40 flights are directly impacted and 160 flights are affected in original solution, run time exceeds 100s.Overall performance of our solution on events in scenario 2 in illustrated in Table IV. Results in scenario 2 also confirm optimization ability of our algorithm. In all four airport closure events, average $24.5 \%$ delay save is achieved. Affected flights also decrease by $10 \%$ compared with "PH" strategy. All four disruptions can be solved within 1 minute.

TABLE I. GROUND DELAY PROGRAM SCENARIOS

\begin{tabular}{|c|c|c|c|c|c|}
\hline Event & Description & Affected Flights & $\begin{array}{c}\text { Grounded } \\
\text { delay } \\
\text { (Minutes) }\end{array}$ & $\begin{array}{c}\text { Maximum } \\
\text { delay(Minutes) }\end{array}$ & $\begin{array}{l}\text { Recovery time } \\
\text { window }\end{array}$ \\
\hline 1 & Morning GDP at one Hub station & First 5 flights arrive to Hub(DFW) & 30 & 60 & $(8: 00-24: 00)$ \\
\hline 2 & Morning GDP at one Hub station & First 10 flights arrive to $\mathrm{Hub}(\mathrm{DFW})$ & 30 & 60 & $(8: 00-24: 00)$ \\
\hline 3 & Morning GDP at one hub station & First 20 flights arrive to $\mathrm{Hub}(\mathrm{DFW})$ & 30 & 60 & $(8: 00-24: 00)$ \\
\hline 4 & Morning GDP at one Hub station & First 5 flights arrive to $\mathrm{Hub}(\mathrm{DFW})$ & 60 & 120 & $(8: 00-24: 00)$ \\
\hline 5 & Morning GDP at one Hub station & First 10 flights arrive to $\mathrm{Hub}(\mathrm{DFW})$ & 60 & 120 & $(8: 00-24: 00)$ \\
\hline 6 & Morning GDP at one hub station & First 20 flights arrive to $\mathrm{Hub}(\mathrm{DFW})$ & 60 & 150 & $(8: 00-24: 00)$ \\
\hline 7 & Morning GDP at two hub stations & $\begin{array}{c}\text { First } 5 \text { flight arrive to Hub(DFW) } \\
\text { and Hub(ORD) }\end{array}$ & 60 & 120 & $(8: 00-24: 00)$ \\
\hline 8 & Morning GDP at two hub stations & $\begin{array}{c}\text { First } 10 \text { flight arrive to Hub(DFW) } \\
\text { and Hub(ORD) }\end{array}$ & 60 & 120 & $(8: 00-24: 00)$ \\
\hline 9 & Morning GDP at two hub stations & $\begin{array}{c}\text { First } 20 \text { flight arrive to Hub(DFW) } \\
\text { and Hub(ORD) }\end{array}$ & $\begin{array}{l}30 \text { for } \mathrm{DFW} \\
60 \text { for ORD }\end{array}$ & 120 & $(8: 00-24: 00)$ \\
\hline
\end{tabular}

TABLE II. AIRPORT CLOSURE SCENARIOS

\begin{tabular}{|c|c|c|c|c|}
\hline Event & Description & Location & $\begin{array}{c}\text { Maximum } \\
\text { delay(Minutes) }\end{array}$ & $\begin{array}{l}\text { Recovery time } \\
\text { window }\end{array}$ \\
\hline 1 & One Hub is closed from $8: 00-8: 30$ & Hub (DFW) & 120 & $(8: 00-24: 00)$ \\
\hline 2 & Two hubs are closed from 8:00-8:30 & Hub (DFW) and Hub(ORD) & 120 & $(8: 00-24: 00)$ \\
\hline 3 & One Hub is closed from 8:00-9:00 & Hub (DFW) & 120 & $(8: 00-24: 00)$ \\
\hline 4 & Two hubs are closed from 8:00-9:00 & Hub (DFW) and Hub(ORD) & 120 & $(8: 00-24: 00)$ \\
\hline
\end{tabular}

TABLE III. OVERALl PERFORMANCE FOR DISRUPTION EVENTS IN SCENARIO 1

\begin{tabular}{|c|c|c|c|c|c|c|c|c|c|c|}
\hline Event & $\begin{array}{c}\text { Affected } \\
\text { flights of } \\
\text { PB }\end{array}$ & $\begin{array}{c}\text { Total } \\
\text { Delay of } \\
\text { PB } \\
\text { (Minutes) }\end{array}$ & $\begin{array}{c}\text { Maximum } \\
\text { flight delay } \\
\text { of PB } \\
\text { (Minutes) }\end{array}$ & $\begin{array}{l}\text { Affected } \\
\text { flights } \\
\text { of } \\
\text { RHAR }\end{array}$ & $\begin{array}{c}\text { Total Delay } \\
\text { of RHAR } \\
\text { (Minutes) }\end{array}$ & $\begin{array}{c}\text { Maximum } \\
\text { flight delay } \\
\text { of RHAR } \\
\text { (Minutes) }\end{array}$ & $\begin{array}{l}\text { No of } \\
\text { cancelled } \\
\text { Flights of } \\
\text { RHAR }\end{array}$ & $\begin{array}{c}\text { No of } \\
\text { deadheaded } \\
\text { crews of } \\
\text { RHAR }\end{array}$ & $\begin{array}{c}\text { Delay } \\
\text { saving }\end{array}$ & $\begin{array}{l}\text { Run time } \\
\text { (seconds) }\end{array}$ \\
\hline gdp_1 & 14 & 300 & 30 & 11 & 240 & 15 & 0 & 0 & $20 \%$ & 3.5 \\
\hline gdp_2 & 30 & 690 & 30 & 24 & 630 & 30 & 0 & 0 & $8.7 \%$ & 7.3 \\
\hline gdp_3 & 62 & 1440 & 30 & 45 & 1230 & 30 & 0 & 0 & $14.5 \%$ & 15.1 \\
\hline gdp_4 & 24 & 930 & 60 & 13 & 510 & 45 & 0 & 2 & $45.2 \%$ & 8.6 \\
\hline gdp_5 & 44 & 1890 & 60 & 32 & 1290 & 60 & 0 & 0 & $31.7 \%$ & 27.7 \\
\hline gdp_6 & 78 & 3645 & 60 & 63 & 2835 & 60 & 0 & 0 & $22.2 \%$ & 77.3 \\
\hline gdp_7 & 49 & 1860 & 60 & 23 & 1140 & 60 & 0 & 4 & $38.7 \%$ & 14.5 \\
\hline gdp_8 & 98 & 4080 & 60 & 53 & 2910 & 60 & 0 & 0 & $28.7 \%$ & 50.8 \\
\hline gdp_9 & 160 & 5580 & 60 & 120 & 4185 & 60 & 0 & 0 & $25.0 \%$ & 101.6 \\
\hline
\end{tabular}

TABLE IV. OVERALl PERFORMANCE FOR DISRUPTION EVENTS IN SCENARIO 2

\begin{tabular}{|c|c|c|c|c|c|c|c|c|c|c|}
\hline Event & $\begin{array}{c}\text { Affected } \\
\text { flights of } \\
\text { PB }\end{array}$ & $\begin{array}{c}\text { Total } \\
\text { Delay of } \\
\text { PB } \\
\text { (Minutes) }\end{array}$ & $\begin{array}{c}\text { Maximum } \\
\text { flight } \\
\text { delay of } \\
\text { PB } \\
\text { (Minutes) }\end{array}$ & $\begin{array}{c}\text { Affected } \\
\text { flights of } \\
\text { RHAR }\end{array}$ & $\begin{array}{c}\text { Total Delay } \\
\text { of RHAR } \\
\text { (Minutes) }\end{array}$ & $\begin{array}{c}\text { Maximum } \\
\text { flight delay } \\
\text { of RHAR } \\
\text { (Minutes) }\end{array}$ & $\begin{array}{c}\text { No of } \\
\text { cancelled } \\
\text { Flights of } \\
\text { RHAR }\end{array}$ & $\begin{array}{c}\text { No of } \\
\text { deadheaded } \\
\text { crews of } \\
\text { RHAR }\end{array}$ & $\begin{array}{l}\text { Delay } \\
\text { saving }\end{array}$ & $\begin{array}{l}\text { Run time } \\
\text { (seconds) }\end{array}$ \\
\hline ac_1 & 26 & 525 & 30 & 21 & 435 & 30 & 0 & 0 & $27.1 \%$ & 4.1 \\
\hline ac_2 & 50 & 1190 & 45 & 40 & 1010 & 45 & 0 & 0 & $15.1 \%$ & 6.9 \\
\hline ac_3 & 53 & 2020 & 60 & 42 & 1455 & 60 & 0 & 0 & $27.9 \%$ & 33.6 \\
\hline ac_4 & 99 & 3885 & 75 & 74 & 2760 & 75 & 0 & 0 & $29.0 \%$ & 41.9 \\
\hline
\end{tabular}




\section{CONCLUSIONS}

In this study, we propose a new integer programming model for integrated airline recovery problem. Our model is based on traditional set partition model for airline scheduling problem in which each resource route represents one decision variable. However, flight delay time is extracted as independent decision variable in the model. By doing so, number of possible resource routes is decreased exponentially and flight delay decision in different resource network is naturally consistent. Airport capacity constraints are also considered in our model which makes resulted recovery solution better reflect operational requirements. One possible way to solve this model is to list all possible resource routes and then solve integrated model. Huge number of possible resource routes makes it intractable. A rolling horizon based algorithm is proposed to efficiently solve this model. Main idea of this algorithm is to divide whole recovery period into several rolling periods and sub-problem is solved along chronological order. The main difference of our rolling horizon based algorithm with traditional rolling horizon idea is that in each period, swapping opportunities are limited but all the flights and resources are considered, purpose of such design is to diving problem by limiting swapping opportunities but circumvent "myopic" of greedy search by considering all the flights and resources within each rolling period.

Two disruption scenarios are simulated to test performance of this algorithm. Among all 10 disruption events, averagely more than $20 \%$ delay saving can be achieved compared to "push-back" strategy. Sensitivity analysis of parameters in our algorithm is also conducted and analysis results reveal that length of rolling period has more impact on run time than on objective value and too small rolling period length isn't encouraged. Unit swap cost has significant impact on several key performance indices. Smaller unit swap cost results in less objective value and total delay but more affected resources. It is necessary to make a trade-off between objective and number of affected resources before deciding unit swap cost.

\section{REFERENCES}

[1] M. Ball, C. Barnhart, G. Nemhauser, A. Odoni, and G. Laporte, "Air transportation: Irregular operations and control," Handbooks in Operations Research and Management Science, vol. 14, no. 1, pp 1-67, 2007.

[2] S. Bratu and C. Barnhart, "Flight operations recovery: New approaches considering passenger recovery," Journal of Scheduling, vol. 9 , no. 3, pp. 279-298, 2006.

[3] D. Teodorović and S. Guberinić, "Optimal dispatching strategy on an airline network after a schedule perturbation," European Journal of Operational Research, vol. 15, no. 2, pp. 178-182, 1984.

[4] D. Teodorović and G. Stojković, "Model for operational daily airline scheduling," Transportation Planning and Technology, vol. 14, no. 4, pp. 273-285, 1990.

[5] D. Teodorovic and G. Stojkovic, "Model to reduce airline schedule disturbances," Journal of Transportation Engineering, vol. 121, no. 4, pp. 324-331, 1995.
[6] A. I. Z. Jarrah, G. Yu, N. Krishnamurthy, and A. Rakshit, "A decision support framework for airline flight cancellations and delays," Transportation Science, vol. 27, no. 3, pp. 266-280, 1993.

[7] J. M. Cao and A. Kanafani, "Real - time decision support for integration of airline flight cancellations and delays part I: Mathematical formulation," Transportation Planning and Technology, vol.20, no. 3, pp. 183-199, 1997.

[8] J. M. Cao and A. Kanafani, "Real - time decision support for integration of airline flight cancellations and delays Part II: Algorithm and computational experiments," Transportation Planning and Technology, vol. 20, no. 3, pp. 201-217, 1997.

[9] S. Yan and D. H. Yang, "A decision support framework for handling schedule perturbation," Transportation Research Part B: Methodological, vol. 30, no. 6, pp. 405-419, 1996.

[10] S. Yan and Y. P. Tu, "Multifleet routing and multistop flight scheduling for schedule perturbation," European Journal of Operational Research, vol. 103, no. 1, pp. 155-169, 1997.

[11] S. Yan and C. G. Lin, "Airline scheduling for the temporary closure of airports," Transportation Science, vol. 31, no. 1, pp. 72-82, 1997.

[12] B. G. Thengvall, J. F. Bard, and G. Yu, "Balancing user preferences for aircraft schedule recovery during irregular operations," Iie Transactions, vol. 32, no. 3, pp. 181-193, 2000.

[13] F. Jonathan, Y. Gang, and F. A. Michael, "Optimizing aircraft routings in response to groundings and delays," IIE Transactions, vol. 33, no. 10, pp. 931-947, 2001.

[14] N. Eggenberg, M. Bierlaire, and M. Salani, "A column generation algorithm for disrupted airline schedules," Technical report, Ecole Polytechnique Federale de Lausanne, 2007.

[15] J. M. Rosenberger, E. L. Johnson, and G. L. Nemhauser, "Rerouting aircraft for airline recovery," Transportation Science, vol. 37, no. 4, pp. 408-421, 2003.

[16] M. D. D. Clarke, "Development of heuristic procedures for flight rescheduling in the aftermath of irregular airline operations," Sc. D Thesis, Massachusetts Institute of Technology, Dept. of Aeronautics and Astronautics, 1998.

[17] M. F. Argüello, J. F. Bard, and G. Yu, "A GRASP for aircraft routing in response to groundings and delays," Journal of Combinatorial Optimization, vol. 1, no. 3, pp. 211-228, 1997.

[18] G. Wei, G. Yu, and M. Song, "Optimization model and algorithm for crew management during airline irregular operations," Journal of Combinatorial Optimization, vol. 1, no. 3, pp. 305-321, 1997.

[19] M. Stojković, F. Soumis, and J. Desrosiers, "The operational airline crew scheduling problem," Transportation Science, vol. 32, no. 3, pp. 232-245, 1998.

[20] A. Abdelghany, G. Ekollu, R. Narasimhan, and K. Abdelghany, "A proactive crew recovery decision support tool for commercial airlines during irregular operations," Annals of Operations Research, vol. 127, no. 1, pp. 309-331, 2004.

[21] L. Lettovský, E. L. Johnson, and G. L. Nemhauser, "Airline crew recovery," Transportation Science, vol. 34, no. 4, pp. 337-348, 2000.

[22] R. Nissen and K. aase, "Duty-period-based network model for crew rescheduling in European airlines," Journal of Scheduling, vol. 9, no. 3, pp. 255-278, 2006

[23] L. Lettovsky, "Airline operations recovery: An optimization approach," in Scholarly Materials and Research at Tech, Publisher: Georgia Institute of Technology, 1997.

[24] J. D. Petersen, G. Sölveling, J. P. Clarke, E. L. Johnson, and S. Shebalov, "An optimization approach to airline integrated recovery," Transportation Science, vol. 46, no. 4, 2012.

[25] N. Eggenberg, M. Salani, and M. Bierlaire, "Constraint-specific recovery network for solving airline recovery problems," Computers \& Operations Research, vol. 37, no. 6, pp. 1014-1026, 2010.

[26] K. F. Abdelghany, A. F. Abdelghany, and G. Ekollu, “An integrated decision support tool for airlines schedule recovery during irregular operations," European Journal of Operational Research, vol. 185, no. 2, pp. 825-848, 2008.

[27] C. Barnhart, E. L. Johnson, G. L. Nemhauser, M. W. P. Savelsbergh, and P. H. Vance, "Branch-and-price: Column generation for solving huge integer programs," Operations Research, vol. 46, no. 3, pp. 316-329, 1998. 


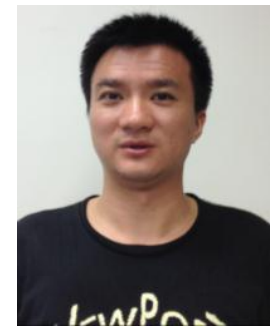

Dong Zhang received the B.A. degree in Industrial Engineering from Zhejiang University, Hangzhou, China in 2009. He is currently working towards the $\mathrm{PhD}$ degree at the Department of Industrial and Manufacturing Systems Engineering, the University of Hong Kong, Hong Kong. His research interests include airline recovery, mathematical programming.

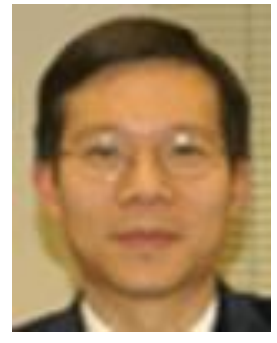

Henry Y. K. Lau received the B.A. degree in engineering science and the D.Phil. degree in robotics from the University of Oxford, Oxford, U.K in 1991.Prior to joining The University of Hong Kong, Hong Kong, as an Associate Professor, he was a College Lecturer at Brasenose College, Oxford, and has been working in the industry as a Senior System Engineer with AEA Technology plc., U.K., working on projects involving system integration and telero-botics systems for the nuclear industry. His research interest includes intelligent automation, automated warehousing, interactive virtual reality, and design and evaluation of automated material-handling systems, such as automated warehouses using simulation and virtual-reality techniques. 